\title{
ON THE ROLE OF ULTRAMODULARITY AND SCHUR CONCAVITY IN THE CONSTRUCTION OF BINARY COPULAS
}

\author{
Erich Peter Klement, Anna Kolesárová, Radko Mesiar \\ AND SUSANNE SAMINGER-PLATZ
}

Abstract. We discuss and stress the role of ultramodularity and Schur concavity in special types of constructions of copulas. After recalling some known ultamodularity-based results, we focus on the so-called $D$-product of a copula and its dual. We show that for each copula $D$ which is ultramodular and Schur concave on the left upper triangle of the unit square, this $D$-product of an arbitrary copula and its dual is again a copula. Several examples and counterexamples are given. Finally, some of our results are generalized to the case of semicopulas and quasi-copulas. Mathematics subject classification (2010): 26B25, 26D20, 62H05.

ula.

Keywords and phrases: Copula, quasi-copula, semicopula, Schur concave copula, ultramodular cop-

\section{REFERENCES}

[1] C. Alsina, M. J. Frank, And B. Schweizer, Associative Functions: Triangular Norms and Copulas, World Scientific, Singapore, 2006.

[2] C. Alsina, R. B. Nelsen, AND B. SChweizer, On the characterization of a class of binary operations on distribution functions, Statist. Probab. Lett. 17: 85-89, 1993.

[3] R. J. Aumann and L. S. Shapley, Values of Non-Atomic Games, Princeton University Press, Princeton, 1974.

[4] R. E. BARLOW AND F. SPIZZICHINO, Schur-concave survival functions and survival analysis, J. Comput. Appl. Math. 46: 437-447, 1993.

[5] B. BASSAN AND F. SPIZZICHINO, Relations among univariate aging, bivariate aging and dependence for exchangeable lifetimes, J. Multivariate Anal. 93: 313-339, 2005.

[6] F. BeCCACECE AND E. Borgonovo, Functional ANOVA, ultramodularity and monotonicity: Applications in multiattribute utility theory, European J. Oper. Res. 210: 326-335, 2011.

[7] T. CAlvo, J. Martin, AND G. Mayor, Convex linear T - $S$ functions: A generalization of Frank's equation, Fuzzy Sets and Systems 226: 67-77, 2013.

[8] P. CApérà̀ ANd C. Genest, Spearman's $\rho$ is larger than Kendall's $\tau$ for positively dependent random variables, J. Nonparametr. Statist. 2: 183-194, 1993.

[9] U. Cherubini, E. Luciano, And W. Vecchiato, Copula Methods in Finance, John Wiley \& Sons Ltd., Chichester, 2004.

[10] D. G. ClAYTON, A model for association in bivariate life tables and its application in epidemiological studies of familial dependency in chronic disease incidence, Biometrika 65: 141-151, 1978.

[11] A. H. ClifFORD, Naturally totally ordered commutative semigroups, Amer. J. Math. 76: 631-646, 1954.

[12] B. DE BAETS, Similarity of fuzzy sets and dominance of random variables: a quest for transitivity, in Preferences and Similarities. Lectures from the 8th International Workshop of the International School for the Synthesis of Expert Knowledge (ISSEK), Udine, Italy, 2006, pages 1-22, Springer, Wien, 2008.

[13] B. DE BAETS, Quasi-copulas: A bridge between fuzzy set theory and probability theory, in V.-N. Huynh, Y. Nakamori, J. Lawry, and M. Inuiguchi, editors, Integrated Uncertainty Management and Applications. Selected Papers Based on the Presentations at the 2010 International Symposium on Integrated Uncertainty Managment and Applications (IUM 2010), Ishikawa, Japan, 2010, page 55, Springer, Berlin, 2010. 
[14] B. De Baets And H. De Meyer, Orthogonal grid constructions of copulas, IEEE Trans. Fuzzy Systems 15: 1053-1062, 2007.

[15] S. DíAz, B. De BaETs, AND S. Montes, General results on the decomposition of transitive fuzzy relations, Fuzzy Optim. Decis. Mak. 9: 1-29, 2010.

[16] A. Dolati AND M. ÚBeda-Flores, Constructing copulas by means of pairs of order statistics, Kybernetika (Prague) 45: 992-1002, 2009.

[17] F. DuRAnte, New results on copulas and related concepts, PhD thesis, Università degli Studi di Lecce, 2006.

[18] F. Durante, Construction of non-exchangeable bivariate distribution functions, Statist. Papers 50: 383-391, 2009.

[19] F. DuRAnte, J. FernándeZ-SÁncheZ, AND C. SEMPI, Sklar's theorem obtained via regularization techniques, Nonlinear Anal. 75: 769-774, 2012.

[20] F. Durante, S. SAminger-Platz, AND P. SAR Koci, Rectangular patchwork for bivariate copulas and tail dependence, Comm. Statist. Theory and Method 38: 2515-2527, 2009.

[21] F. Durante And C. Sempi, Copula and Schur-concavity, Int. Math. J. 3: 893-905, 2003.

[22] F. Durante and C. Sempi, Semicopula, Kybernetika (Prague), 41: 315-328, 2005.

[23] M. J. Frank, On the simultaneous associativity of $F(x, y)$ and $x+y-F(x, y)$, Aequationes Math. 19: 194-226, 1979.

[24] C. Genest, J. J. Quesada-Molina, J. A. Rodríguez-Lallena, And C. SemPi, A characterization of quasi-copulas, J. Multivariate Anal. 69: 193-205, 1999.

[25] C. Genest AND L.-P. Rivest, Statistical inference procedures for bivariate Archimedean copulas, Journal of the American Statistical Association 88: 1034-1043, 1993.

[26] M. Goncalves, N. Kolev, And A. Fabris, Bounds for distorted risk measures, Econ. Qual. Control 23: 243-255, 2008.

[27] W.-M. Gong, H. Sun, AND Y.-M. CHU, The Schur convexity for the generalized Muirhead mean, J. Math. Inequal. 8: 855-862, 2014.

[28] M. Grabisch, J.-L. Marichal, R. Mesiar, and E. Pap, Aggregation Functions, Cambridge University Press, Cambridge, 2009.

[29] P. HáJeK And R. Mesiar, On copulas, quasicopulas and fuzzy logic, Soft Computing 12: 1239$1243,2008$.

[30] H. JoE, Multivariate Models and Dependence Concepts, Chapman \& Hall, London, 1997.

[31] A. Khoudraji, Contributions à l'étude des copules et à la modélisation des valeurs extrêmes bivariées, PhD thesis, Université Laval, Québec, 1995.

[32] E. P. Klement, A. Koles Árová, R. Mesiar, And C. Sempi, Copulas constructed from horizontal sections, Comm. Statist. Theory Methods 36: 2901-2911, 2007.

[33] E. P. Klement, M. Manzi, and R. Mesiar, Ultramodular aggregation functions, Inform. Sci. 181: 4101-4111, 2011.

[34] E. P. Klement, M. Manzi, And R. Mesiar, Ultramodularity and copulas, Rocky Mountain J. Math. 44: 189-202, 2014.

[35] E. P. Klement, R. Mesiar, And E. Pap, Triangular Norms, Kluwer Academic Publishers, Dordrecht, 2000.

[36] E. P. Klement, R. Mesiar, And E. PAP, A universal integral as common frame for Choquet and Sugeno integral, IEEE Trans. Fuzzy Systems 18: 178-187, 2010.

[37] A. Koles ÁRovÁ, 1-Lipschitz aggregation operators and quasi-copulas, Kybernetika (Prague) 39: 615-629, 2003.

[38] A. KolesárovÁ, R. Mesiar, AND J. KaliCKÁ, On a new construction of 1 -Lipschitz aggregation functions, quasi-copulas and copulas, Fuzzy Sets and Systems 226: 19-31, 2013.

[39] D.-M. LI AND H.-N. SHI, Schur convexity and Schur-geometrically concavity of generalized exponent mean, J. Math. Inequal. 3: 217-225, 2009.

[40] E. Liebscher, Construction of asymmetric multivariate copulas, J. Multivariate Anal. 99: 2234$2250,2008$.

[41] C. M. Ling, Representation of associative functions, Publ. Math. Debrecen 12: 189-212, 1965.

[42] M. Marinacci And L. Montrucchio, Ultramodular functions, Math. Oper. Res. 30: 311-332, 2005.

[43] M. Marinacci And L. Montrucchio, On concavity and supermodularity, J. Math. Anal. Appl. 344: 642-654, 2008. 
[44] A. W. Marshall and I. Olkin, Majorization in multivariate distributions, Ann. Statist. 2: 11891200, 1974.

[45] A. W. Marshall, I. Olkin, And B. C. Arnold, Inequalities: Theory of Majorization and Its Applications, Springer, New York, second edition, 2011.

[46] R. Mesiar And J. Szolgay, $W$-ordinal sums of copulas and quasi-copulas, In Proceedings MAGIA \& UWPM 2004, pages 78-83, Bratislava, 2004, Slovak University of Technology, Publishing House of STU.

[47] R. Moynihan, On $\tau_{T}$ semigroups of probability distribution functions II, Aequationes Math. 17: $19-40,1978$.

[48] A. MÜller AND M. SCARSINI, Stochastic comparison of random vectors with a common copula, Math. Oper. Res. 26: 723-740, 2001.

[49] R. B. Nelsen, An Introduction to Copulas, Lecture Notes in Statistics 139, Springer, New York, second edition, 2006.

[50] R. B. Nelsen And G. A. Fredricks, Diagonal copulas, in V. Beneš and J. Štěpán, editors, distributions with Given Marginals and Moment Problems, pp. 121-127. Kluwer Academic Publishers, Dordrecht, 1997.

[51] R. B. NELSEN AND M. ÚBedA-Flores, The lattice-theoretic structure of sets of bivariate copulas and quasi-copulas, Comptes Rendus Mathematique 341: 583-586, 2005.

[52] S. E. Nevius, F. Proschan, and J. Sethuraman, Schur functions in statistics, II. Stochastic majorization, Ann. Statist. 5: 263-273, 1977.

[53] F. Proschan and J. Sethuraman, Schur functions in statistics, I. The preservation theorem, Ann. Statist. 5: 256-262, 1977.

[54] A. W. Roberts and D. E. Varberg, Convex functions, Academic Press, New York, 1973.

[55] I. RovenţA, A note on Schur-concave functions, J. Inequal. Appl., pages 2012:159, 9, 2012.

[56] E. SAINIO, E. TURUNEN, AND R. MEsiaR, A characterization of fuzzy implications generated by generalized quantifiers, Fuzzy Sets and Systems 159: 491-499, 2008.

[57] I. SCHUR, Über eine Klasse von Mittelbildungen mit Anwendungen auf die Determinantentheorie, Sitzungsber. Berl. Math. Ges. 22: 9-20, 1923.

[58] B. SchweIzer And A. Sklar, Associative functions and abstract semigroups, Publ. Math. Debrecen 10: 69-81, 1963.

[59] B. Schweizer And A. Sklar, Probabilistic Metric Spaces, North-Holland, New York, 1983 (updated and reprinted under the same title by Dover Publications, Mineola, 2006).

[60] M. Shaked and J. G. Shanthikumar, Stochastic orders, Springer, New York, 2007.

[61] H.-N. SHI, Schur-convex functions related to Hadamard-type inequalities, J. Math. Inequal. 1: 127136, 2007.

[62] H.-N. SHI AND J. ZHANG, Schur-convexity, Schur geometric and Schur harmonic convexities of dual form of a class symmetric functions, J. Math. Inequal. 8: 349-358, 2014.

[63] H.-N. SHI, J. ZHANG, AND C. GU, New proofs of Schur-concavity for a class of symmetric functions, J. Inequal. Appl., pages 2012:12, 4, 2012.

[64] A. SKLAR, Fonctions de répartition à $n$ dimensions et leurs marges, Publ. Inst. Statist. Univ. Paris 8: 229-231, 1959.

[65] F. SpIZZICHINo, Subjective Probability Models for Lifetimes, Chapman \& Hall/CRC, Boca Raton, 2001.

[66] M. Sugeno, Theory of fuzzy integrals and its applications, $\mathrm{PhD}$ thesis, Tokyo Institute of Technology, 1974.

[67] S. WEBER, A general concept of fuzzy connectives, negations and implications based on $t$-norms and $t$-conorms, Fuzzy Sets and Systems 11: 115-134, 1983.

[68] E. M. Wright, An inequality for convex functions, Amer. Math. Monthly 61: 620-622, 1954.

[69] R. R. YAGER, Joint cumulative distribution functions for Dempster-Shafer belief structures using copulas, Fuzzy Optim. Decis. Mak. 12: 393-414, 2013. 